\title{
The Impact of a Changing Southern Hemisphere Annular Mode on Antarctic Peninsula Summer Temperatures
}

\author{
GARETH J. MARSHALL \\ British Antarctic Survey, Natural Environment Research Council, Cambridge, United Kingdom \\ ANDREW ORR \\ Department of Space and Climate Physics, University College London, London, United Kingdom \\ NICOLE P. M. VAN LIPZIG \\ Physical and Regional Geography Research Group, K.U. Leuven, Leuven, Belgium \\ JoHn C. KING \\ British Antarctic Survey, Natural Environment Research Council, Cambridge, United Kingdom
}

(Manuscript received 30 May 2005, in final form 11 October 2005)

\begin{abstract}
Since the mid-1960s, rapid regional summer warming has occurred on the east coast of the northern Antarctic Peninsula, with near-surface temperatures increasing by more than $2^{\circ} \mathrm{C}$. This warming has contributed significantly to the collapse of the northern sections of the Larsen Ice Shelf. Coincident with this warming, the summer Southern Hemisphere Annular Mode (SAM) has exhibited a marked trend, suggested by modeling studies to be predominantly a response to anthropogenic forcing, resulting in increased westerlies across the northern peninsula.

Observations and reanalysis data are utilized to demonstrate that the changing SAM has played a key role in driving this local summer warming. It is proposed that the stronger summer westerly winds reduce the blocking effect of the Antarctic Peninsula and lead to a higher frequency of air masses being advected eastward over the orographic barrier of the northern Antarctic Peninsula. When this occurs, a combination of a climatological temperature gradient across the barrier and the formation of a föhn wind on the lee side typically results in a summer near-surface temperature sensitivity to the SAM that is 3 times greater on the eastern side of the peninsula than on the west. SAM variability is also shown to play a less important role in determining summer temperatures at stations west of the barrier in the northern peninsula $\left(\sim 62^{\circ} \mathrm{S}\right)$, both at the surface and throughout the troposphere. This is in contrast to a station farther south $\left(\sim 65^{\circ} \mathrm{S}\right)$ where the SAM exerts little influence.
\end{abstract}

\section{Introduction}

The temperature of the northern Antarctic Peninsula region (as shown in Fig. 1) has undergone significant change over the last $50 \mathrm{yr}$, the period of instrumental record. In contrast to most of the Antarctic continent, which demonstrates very little significant change (Turner et al. 2005; more information available online at http://www.antarctica.ac.uk/met/gjma/temps.html),

Corresponding author address: Dr. Gareth Marshall, British Antarctic Survey, High Cross Madingley Rd., Cambridge CB3 OET, United Kingdom.

E-mail: gjma@pcmail.nbs.ac.uk annual near-surface temperatures in the central western peninsula have increased at a much higher rate than the global average, and possibly higher than anywhere else on the earth over this period. At the Faraday station (see Fig. 1; note that this station became Vernadsky in 1996, when its operation passed to the Ukraine) the near-surface warming from 1951 to 2004 was $2.94^{\circ} \mathrm{C}$, significant at the $<1 \%$ level, whereas the global average was $0.52^{\circ} \mathrm{C}$ [based on the Goddard Institute for Space Studies data; see Hansen et al. (2001) for details]. Climate proxies suggest that this warming has led to regional temperatures that are unprecedented over the last $2000 \mathrm{yr}$ (Vaughan et al. 2003).

Although winter is the season of greatest warming at 
TABLE 1. Annual and seasonal trends in the SAM from 1965 to 2000 . Units are decade ${ }^{-1}$. Significant trends $(<1 \%)$ are shown by the asterisks.

\begin{tabular}{ccccc}
\hline \hline Annual & Autumn (MAM) & Winter (JJA) & Spring (SON) & Summer (DJF) \\
\hline$+1.08 \pm 0.36^{*}$ & $+0.93 \pm 0.29^{*}$ & $-0.04 \pm 0.50$ & $+0.32 \pm 0.52$ & $+1.11 \pm 0.44^{*}$ \\
\hline
\end{tabular}

Faraday, on the west coast (cf. Fig. 1), the southward migration of the $0^{\circ} \mathrm{C}$ isotherm during summer is responsible for the clearest signs of regional climate change: in total more than $13500 \mathrm{~km}^{2}$ of ice shelves have disintegrated from the peninsula in the last $30 \mathrm{yr}$ (Scambos et al. 2004). Most recent has been the collapse of the northern sections of the Larsen Ice Shelf on the eastern side. Marine sediments from below where the farthest south of these sections, the Larsen B shelf, was formerly located, indicate that its collapse is unique within the Holocene period (Domack et al. 2005). Although basal melting may have played a role in the ice shelf breakup (Shepherd et al. 2003), crevasse propagation due to percolating surface meltwater is generally thought to be the primary mechanism involved (Scambos et al. 2000, 2003; van den Broeke 2005). This is a direct consequence of marked summer air temperature increases in the 1990s. Indeed, in recent decades the summer warming at stations in the northeast of the region has exceeded that in the west: between 1965 and 2004 the summer near-surface temperature increase at Esperanza (see Fig. 1) and Faraday was $2.09^{\circ}$ and $0.84^{\circ} \mathrm{C}$, respectively. Since the removal of the ice shelves, observations of regional glaciers have revealed both surface lowering and acceleration, thus leading to a eustatic sea level rise (e.g., De Angelis and Skvarca 2003; Rignot et al. 2004).

The atmospheric circulation of the peninsula region has also changed significantly during the last few decades. The principal mode of variability in the Southern Hemisphere ( $\mathrm{SH}$ ) circulation, the SH Annular Mode (SAM), began a positive phase shift in the mid-1960s (Marshall 2003), which has resulted in increased (reduced) pressures in the $\mathrm{SH}$ midlatitudes (the Antarctic region). The trends in the SAM are statistically significant annually, in autumn and especially in summer (cf. Table 1). Observation-based time series of the SAM indicate similarly high summer values in the early 1960s (Marshall et al. 2004; Jones and Widmann 2004), signifying that natural variability may have played a role in driving these trends. Indeed, recent studies have linked ENSO and SAM variability during the austral summer (Carvalho et al. 2005; L'Heureux and Thompson 2006). However, several model studies agree in suggesting that anthropogenic change-through a combination of greenhouse gas increases and ozone depletion-is pri- marily responsible for this climatic shift (e.g., Kushner et al. 2001; Gillett and Thompson 2003; Marshall et al. 2004; Shindell and Schmidt 2004).

Changes in the meridional pressure gradient associated with a more positive SAM have strengthened the circumpolar vortex and intensified the westerlies that encircle Antarctica and impinge upon the northwestern peninsula (Marshall 2002). Statistical analysis by both Thompson and Solomon (2002) and Kwok and Comiso (2002), using independent temperature datasets, revealed strong positive correlations between the SAM and temperatures across the peninsula region, suggesting that the increasing westerlies have played a role in the warming there. More recently, some studies have begun to examine the possible physical mechanisms linking changes in the SAM and regional temperatures. Van den Broeke and van Lipzig (2003) proposed that during the positive phase of the winter SAM, the South Atlantic storm center is displaced, cutting off the atmospheric branch of the Weddell gyre, and leading subsequently to a rise in temperature over the Weddell Sea and the peninsula region. Liu et al. (2004) suggested that during the positive phase of the SAM a strong cyclonic circulation west of the peninsula results in an increased poleward heat flux into the region, which, combined with sea ice divergence away from the coast, leads to warmer peninsula temperatures. Orr et al. (2004) proposed that the blocking effect of the peninsula orography (a mountain chain typically $1.5-2.0 \mathrm{~km}$ high) at lower levels increases with the strength of the westerly flow, causing the wind to veer and become more northerly, again leading to greater transport of relatively warm air along the western side of the peninsula. However, the authors of this last paper also suggested that beyond a critical threshold stronger westerlies are more likely to pass over the peninsula. Thus, relatively warm maritime air from the west will reach the colder continental east with more frequency, causing warming on the eastern peninsula as well.

In this paper, we hypothesize that this latter physical mechanism may explain why the recent summer warming in the northeast peninsula is so large and, consequently, the recent disintegration of the northern sections of the Larsen Ice Shelf. We examine the spatial and temporal relationships between the SAM and the peninsula region temperatures using observations and 


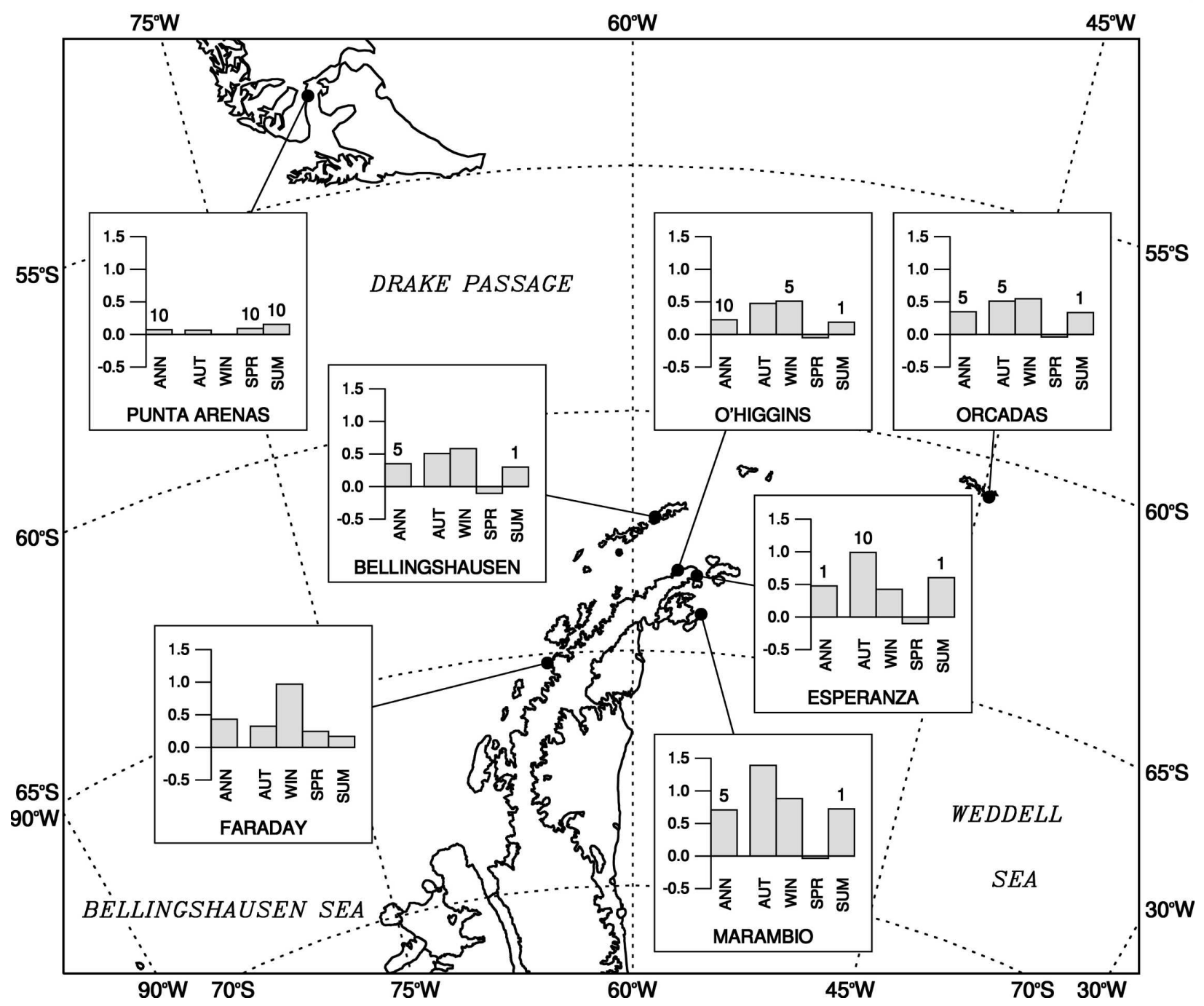

FIG. 1. The northern Antarctic Peninsula and southern South American region showing the location of stations examined in this study. The graphs show the change in annual and seasonal-autumn: March-May (MAM), winter: June-August (JJA), spring: September-November (SON), and summer: December-February (DJF)-near-surface temperature coincident with the positive trend in the SAM that began in the mid-1960s. The trends are calculated over 1965-2000, except for Bellingshausen (1968-2000) and Marambio (1970-2000). Units are ${ }^{\circ} \mathrm{C}$ decade ${ }^{-1}$. Values are shown if the significance level of the trend is at the $<1 \%,<5 \%$, or $<10 \%$ level.

reanalysis data. First, near-surface temperatures from seven meteorological stations in the northern Antarctic Peninsula and southern South America region are compared to the SAM over the 43-yr period from 1958 to 2000. In addition, tropospheric temperatures and circulation changes are examined using the recently available complete upper-air dataset from Bellingshausen station in the northern peninsula (see Fig. 1). Statistical relationships between peninsula temperatures and the SAM are analyzed on annual and seasonal time scales in order to set those in summer in context. Using regression coefficients, the proportion of the observed warming due to the changes in the SAM is estimated. Second, data from the 40-Year European Centre for
Medium-Range Weather Forecasts (ECMWF) ReAnalysis (ERA-40) are employed to investigate the spatial pattern of regional variability in key meteorological parameters associated with changes in the summer SAM. Further papers (A. Orr et al. 2006, unpublished manuscript; N. P. M. van Lipzig et al. 2006, unpublished manuscript) utilize both laboratory and regional case study and climate model studies to provide further details on the physical processes described in this work.

In section 2 of this paper, the various datasets and statistical methodology used are described, including an evaluation of ERA-40 data in the region examined. The spatial and seasonal variability of the strength of the 
TABLE 2. Location and near-surface temperature data availability of the northern peninsula region stations analyzed in this study.

\begin{tabular}{lcccr}
\hline \hline \multicolumn{1}{c}{ Station } & Lat & Lon & Data availability & Missing months \\
\hline Bellingshausen & $62^{\circ} 12^{\prime} \mathrm{S}$ & $58^{\circ} 58^{\prime} \mathrm{W}$ & Mar 1968-Dec 2000 & 0 \\
Esperanza & $63^{\circ} 24^{\prime} \mathrm{S}$ & $56^{\circ} 59^{\prime} \mathrm{W}$ & Jan 1958-Dec 2000 & 6 \\
Faraday & $65^{\circ} 15^{\prime} \mathrm{S}$ & $64^{\circ} 16^{\prime} \mathrm{W}$ & Jan 1958-Dec 2000 & 0 \\
Marambio & $64^{\circ} 15^{\prime} \mathrm{S}$ & $56^{\circ} 39^{\prime} \mathrm{W}$ & Sep 1970-Dec 2000 & 27 \\
O'Higgins & $63^{\circ} 18^{\prime} \mathrm{S}$ & $57^{\circ} 54^{\prime} \mathrm{W}$ & Jan 1963-Dec 2000 & 18 \\
Orcadas & $60^{\circ} 45^{\prime} \mathrm{S}$ & $44^{\circ} 43^{\prime} \mathrm{W}$ & Jan 1958-Dec 2000 & 1 \\
Punta Arenas & $53^{\circ} 00^{\prime} \mathrm{S}$ & $70^{\circ} 51^{\prime} \mathrm{W}$ & Jan 1958-Dec 2000 & 13
\end{tabular}

statistical relationships between the SAM and northern peninsula temperatures are documented in section 3. In section 4 they are discussed with reference to the regional climate anomalies associated with high (strongly positive) or low (strongly negative) SAM as revealed by the ERA-40 fields. Finally, in section 5, we present a discussion of the work: the proposed mechanisms linking changes in the SAM to the rapid rise in northeast peninsula summer temperatures are examined further using additional surface observations. In addition, the principal conclusions are outlined in this section.

\section{Data and methodology}

\section{a. The SAM index}

The principal SAM index utilized in this study was developed by Marshall (2003) from monthly mean sea level pressure (MSLP) data at 12 stations in the SH extratropics. It is currently available for the period 1958-2000 (although a slightly altered up-to-date version can now be obtained online at http://www.nercbas.ac.uk/icd/gjma/sam.html). Note that there are several definitions of the SAM available (e.g., Gong and Wang 1999; Thompson and Wallace 2000; Thompson and Solomon 2002; Jones and Widmann 2004). Marshall (2003) used the basic definition of Gong and Wang (1999), which is the normalized zonal pressure difference between $40^{\circ}$ and $65^{\circ} \mathrm{S}$ (representing mid- and high southern latitudes, respectively). However, because of known spurious temporal trends in reanalysis MSLP data around Antarctica, he utilized data from appropriately located stations-six each at approximately $40^{\circ}$ and $65^{\circ} \mathrm{S}$ - to produce observation-based zonal mean MSLP values with which to compute the SAM index. The principal advantages of the Marshall (2003) index are its simplicity and temporal consistency across its entire time span and between different seasons. The main disadvantage compared to (empirical orthogonal function) EOF-based SAM indices is that it does not account for the changing nonzonal spatial SAM variability across different seasons. However, as this study is primarily concerned with only one season (summer), this is not a significant issue here. In addition, the temporal extent of the Marshall (2003) index is limited to the period from the late 1950s, when most Antarctic observations began. Once again, this is not a problem in the present study where we concentrate on the period of the recent positive trend in the summer SAM, from 1965 onward.

In addition a monthly SAM index produced by the US National Weather Service Climate Prediction Center (CPC; available online at http://www.cpc.ncep. noaa.gov/products/precip/CWlink/daily_ao_index/aao/ month_aao_index.shtml.) is used to test correlations against more recent data (see section 5). This index is based on the first EOF of the 700-hPa geopotential height field obtained from the National Centers for Environmental Prediction-National Center for Atmospheric Research (NCEP-NCAR) reanalysis. It begins in 1979 and is updated monthly.

\section{b. Surface station observations}

The locations of the seven meteorological stations from which near-surface temperature data were examined are shown in Fig. 1. Station coordinates and data availability are summarized in Table 2. Antarctic data were taken principally from the Scientific Committee for Antarctic Research (SCAR) Reference Antarctic Data for Environmental Research (READER) project (Turner et al. 2004), which produced a definitive set of monthly mean values of basic meteorological parameters at Antarctic stations. (This dataset is available online at http://www.antarctica.ac.uk/met/READER/). Six-hourly synoptic data from Esperanza were obtained from the Global Telecommunication System (GTS) via the Met Office. Data from Punta Arenas were kindly supplied by Dr. Phil Jones of the Climatic Research Unit, University of East Anglia.

\section{c. Bellingshausen free-air observations}

The complete free-air temperature dataset from Bellingshausen, where the upper-air program commenced in May 1969 and stopped in January 1999, were also acquired as part of the READER project. Data were 
examined at standard levels from 850 to $20 \mathrm{hPa}$. Random errors (outliers) were removed from the daily data using methodology from the fields of resistant, robust, and nonparametric techniques (Lanzante 1996). Typically, this reduced the available observations at each pressure level by $\sim 0.2 \%$. Monthly mean values were produced following the procedures laid down by the Met Office (1979) whereby the calculated mean is considered representative for the entire month provided that at least ten observations exist for that month and that no gap between observations exceeds 4 days. Reasonably complete monthly time series were produced for the troposphere, but with an increasing number of missing data in the stratosphere, especially during the austral winter. Reference is also made to a free-air temperature record from Faraday from 1956 to 1999; this dataset is a synthesis of observations and reanalysis data and its construction is described in Marshall et al. (2002).

\section{d. Sea ice concentration data}

Monthly sea ice concentration data were acquired from the National Snow and Ice Data Center (NSIDC). These data were produced using a modified version of the Bootstrap algorithm (Comiso 1995) with revised tie points improving the temporal consistency of the dataset. An ice concentration of 0.15 was used to define the ice edge.

\section{e. ERA-40 reanalysis data}

ERA-40 is the recently completed ECMWF reanalysis covering the 45-yr period from mid-1957 to mid-2002 Uppala et al. 2005; more information available online at http://www.ecmwf.int/research/era/). Marshall (2003) demonstrated that ERA-40 is currently the reanalysis that best represents MSLP at SH high latitudes, although significant biases may occur in individual months prior to the assimilation of satellite sounder data. This first occurred in 1973, with temperatures from the Vertical Temperature Profile Radiometer (VTPR) being utilized. A subsequent further improvement took place in 1979, with the assimilation of both temperature and humidity from the Television Infrared Observational Satellite (TIROS) Operational Vertical Sounder (TOVS) instrument.

These were the first systematic observations over the Southern Ocean and the improvements they made to the ERA-40 MSLP field at three stations in the region of study can be seen in Fig. 2. This shows the bias in reanalysis MSLP as compared to station observations, with the ERA-40 fields being interpolated to the nearest $0.1^{\circ}$ latitude-longitude. Outliers after 1979 are likely
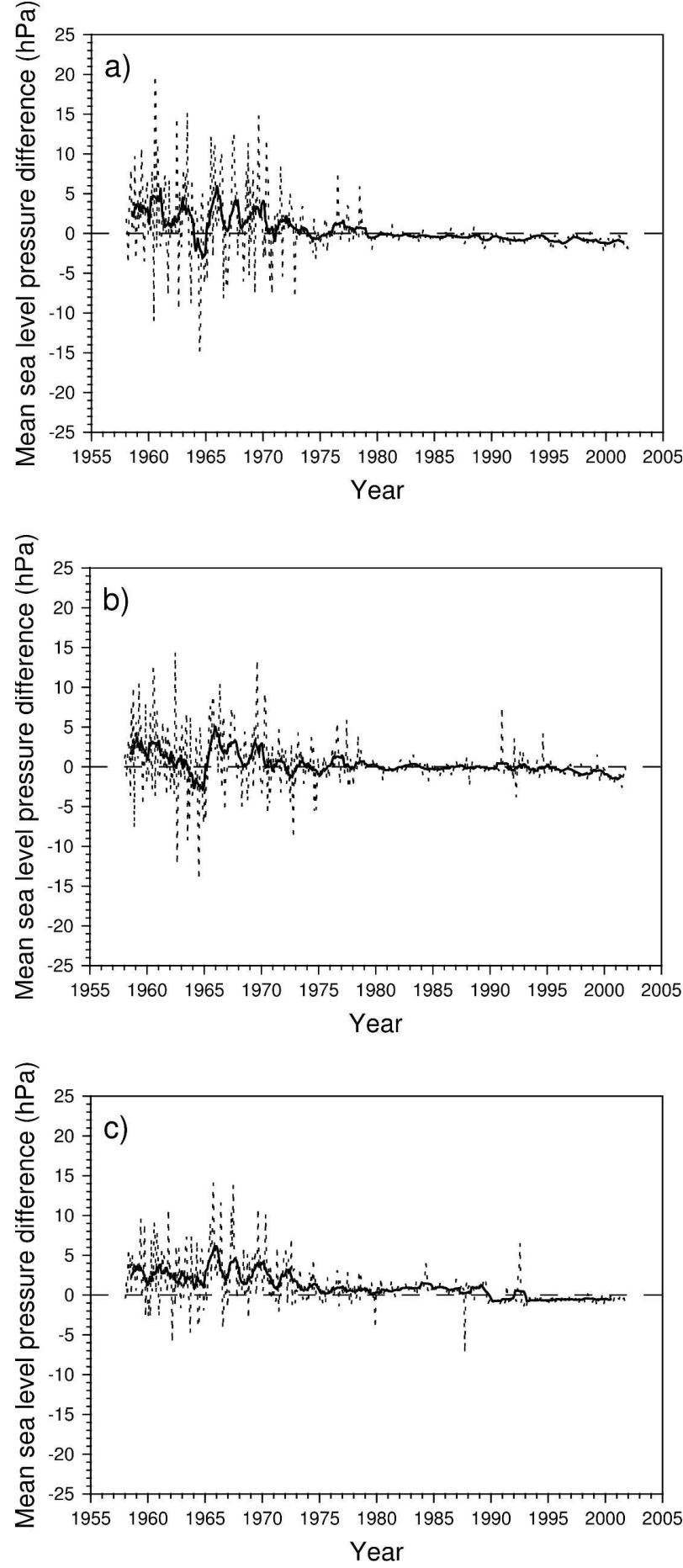

FIG. 2. Bias in the ERA-40 MSLP at (a) Faraday, (b) Orcadas, and (c) Punta Arenas. The dotted line is the monthly data and the solid line is a 12 -month running mean. Units are $\mathrm{hPa}$.

to be errors in the observational dataset-introduced during telecommunication for example-rather than in the reanalysis. Note the apparent negative "drift" in the bias at Faraday (Fig. 2a) and to a lesser extent at Or- 
cadas (Fig. 2b). Although this suggests an instrument problem, we know that the barometer at Faraday is calibrated regularly (J. Shanklin 2004, British Antarctic Survey, personal communication). At Punta Arenas (Fig. 2c), a step jump can be seen in 1989, when the ERA-40 bias switches from positive to negative. The jump does not exist at other stations, so is unlikely to be an artifact of the reanalysis, and is too small to be a shift from station to sea level pressure. Therefore, it may have resulted from a change in instrument, station location, and/or a calibration error.

In Fig. 3 the ERA-40 bias in near-surface temperatures at the same three stations is shown. Prior to 1979, this is significant at Faraday (cf. Fig. 3a) but thereafter the bias is generally smaller and reasonably constant at about $-1.5^{\circ} \mathrm{C}$. At Orcadas and especially Punta Arenas, the bias is very small indeed. Note that most of the stations examined in this study, all located near the coast, are actually positioned on the seaward side of the ERA-40 land-sea mask. Due to the land-sea contrast in, for example, surface fluxes, these stations might not be representative of the model grid box, which may result in an offset between measurements and model output.

The other ERA-40 data used in this study are the 10-m winds, which are assumed to be similarly accurate to MSLP after 1979. Note that the significant impact of local orography on surface wind direction in the peninsula region means there is little point in comparing model output at the horizontal resolution of ERA-40 $(\sim 125 \mathrm{~km})$ against station observations. These results give us confidence that the post-1979 ERA-40 data can be usefully employed for studying recent variability and trends in meteorological parameters in the Antarctic Peninsula region. A more comprehensive analysis of ERA-40 MSLP and near-surface temperatures for the southern extratropics is given by Bromwich and Fogt (2004).

\section{f. Statistical techniques}

The magnitude of the trends described in this paper is computed using a standard least squares method, while the methodology used to calculate the significance levels is based upon Santer et al. (2000). Briefly, an effective sample size is calculated based on the lag- 1 autocorrelation coefficient of the regression residuals. This effective sample size is used for the computation of the standard error and in indexing the critical values of the Student's $t$ distribution. The significance level of the trend, that is the likelihood of the null hypothesis-that there is no trend-being erroneously rejected is given if it is less than $10 \%, 5 \%$, or $1 \%$.
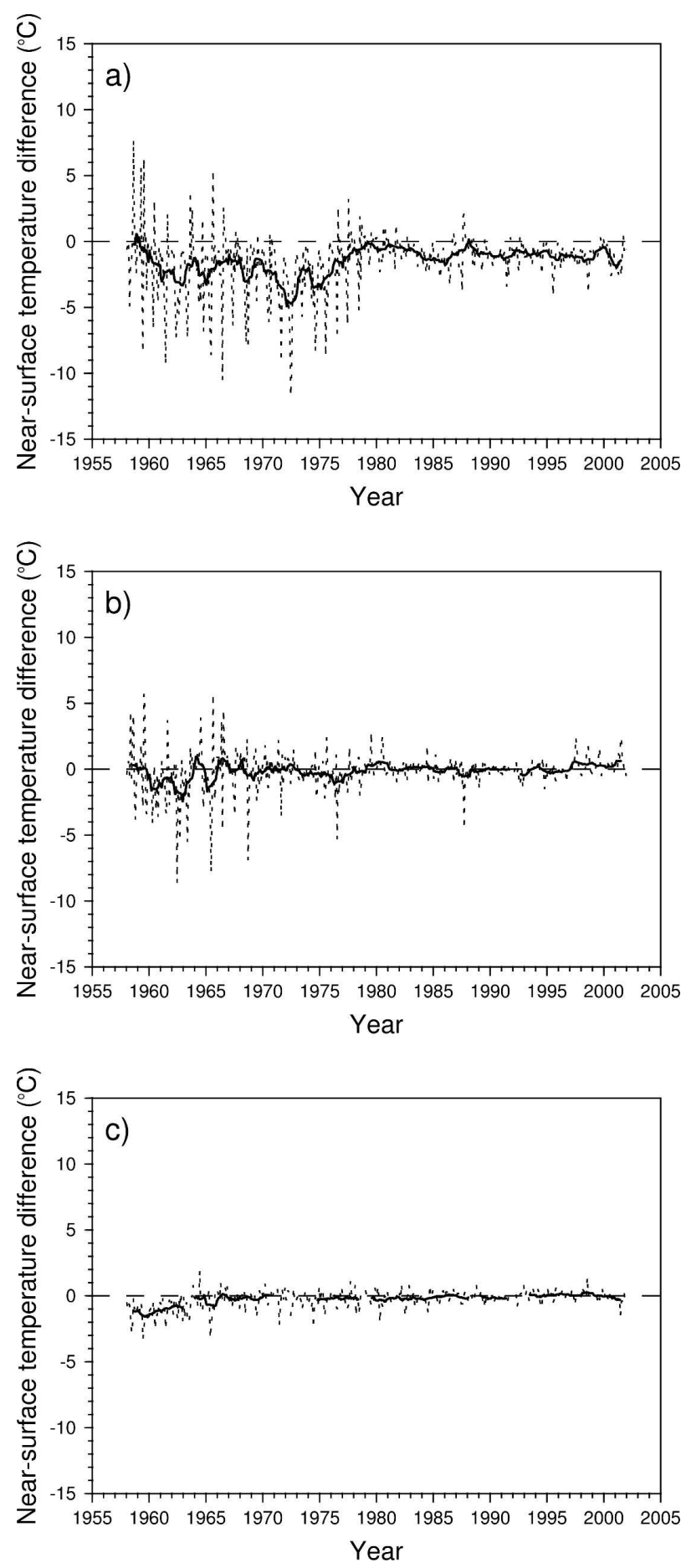

FIG. 3. Bias in the ERA-40 near-surface temperature at (a) Faraday, (b) Orcadas, and (c) Punta Arenas. The dotted line is the monthly data and the solid line is a 12 -month running mean. Units are ${ }^{\circ} \mathrm{C}$.

Correlation and regression coefficients between the SAM and temperatures have been derived principally using detrended data. This methodology provides a minimum value for the derived coefficients as it as- 
TABLE 3. Annual and seasonal correlation and the absolute value of the regression coefficients (in parentheses) between the detrended SAM and detrended peninsula region near-surface temperature observations [1958-2000; except Bellingshausen (1968-2000) and Marambio (1970-2000)]. Significant correlations are shown by the asterisks; $*<1 \%$; $* * 5 \%$; and $* * *<10 \%$. Regression coefficient units are ${ }^{\circ} \mathrm{C}$ per unit change in the SAM.

\begin{tabular}{|c|c|c|c|c|c|c|c|c|c|c|}
\hline \multirow{2}{*}{$\frac{\text { Stations }}{\text { Bellingshausen }}$} & \multicolumn{2}{|c|}{ Annual } & \multicolumn{2}{|c|}{ Autumn (MAM) } & \multicolumn{2}{|c|}{ Winter (JJA) } & \multicolumn{2}{|c|}{ Spring (SON) } & \multicolumn{2}{|c|}{ Summer (DJF) } \\
\hline & $0.46^{*}$ & $(0.23)$ & $0.52 *$ & $(0.36)$ & $0.42 * *$ & $(0.45)$ & 0.08 & $(0.04)$ & 0.12 & $(0.03)$ \\
\hline Esperanza & $0.28^{* * *}$ & $(0.18)$ & $0.40 *$ & $(0.52)$ & $0.35^{*}$ & $(0.42)$ & 0.16 & $(0.12)$ & $0.47 *$ & $(0.21)$ \\
\hline Faraday & 0.00 & $(0.00)$ & 0.10 & $(0.08)$ & 0.13 & $(0.21)$ & $-0.27 * * *$ & $(0.23)$ & -0.12 & $(0.04)$ \\
\hline Marambio & $0.44 * *$ & $(0.28)$ & $0.47 *$ & $(0.76)$ & 0.28 & $(0.43)$ & $0.37 * * *$ & $(0.34)$ & $0.36^{* * *}$ & $(0.15)$ \\
\hline O’Higgins & $0.49^{*}$ & $(0.20)$ & $0.54 *$ & $(0.40)$ & $0.33 * *$ & $(0.29)$ & 0.16 & $(0.08)$ & 0.25 & $(0.07)$ \\
\hline Orcadas & $0.33 * *$ & $(0.18)$ & $0.44 *$ & $(0.37)$ & $0.32 * *$ & $(0.41)$ & 0.10 & $(0.07)$ & $0.29 * * *$ & $(0.04)$ \\
\hline Punta Arenas & $0.48 *$ & $(0.11)$ & 0.04 & $(0.01)$ & $0.37 * *$ & $(0.15)$ & 0.23 & $(0.06)$ & 0.16 & $(0.05)$ \\
\hline
\end{tabular}

sumes that there is no link between linear trends in the predictor (SAM) and predictand (temperature). Using the original, undetrended data assumes that the entire trend in the predictand that covaries with the predictor is due to the latter, and hence derived coefficients are maximum possible values. We consider that this paper provides a plausible physical mechanism linking the SAM and summer temperatures in some regions of the peninsula: therefore, we believe that actual statistical values will be greater than the minimum possible. Thus, while we generally take a "conservative" approach in using the detrended data to calculate correlation and regression coefficients, we sometimes provide a range of possible values, using the detrended and original data to provide minimum and maximum limits, respectively.

Statistical coefficients between the SAM and temperatures were determined for a SAM computed only from those periods when temperature data were available. However, when calculating the contribution to changing temperatures attributable to the SAM, then the complete time series was used. Regression coefficients are calculated for a positive unit change in the SAM index [i.e., a regression coefficient of $0.5(-0.5)$ means that if the SAM index increases by 1 then the temperature warms (cools) by $0.5^{\circ} \mathrm{C}$ ].

\section{Results}

\section{a. Correlation and regression statistics between the $S A M$ and regional near-surface temperatures}

Annual and seasonal correlation and regression coefficients between the detrended SAM index and detrended near-surface temperatures at the seven meteorological stations are given in Table 3 . With the exception of Faraday $(r=0.00)$, the annual correlation coefficients $(r=0.28-0.49)$ indicate statistically significant relationships exist between the mean annual SAM index and near-surface temperatures in the northern peninsula region. Equivalent coefficients between the original time series reveal, as expected, higher values of $r$, up to 0.57 , with all the correlations (apart from at Faraday) being significant at the $<1 \%$ level.

The majority of the stations examined demonstrate statistically significant relationships between the SAM and temperatures in autumn and most of these have their largest correlation coefficient in this season (cf. Table 3). However, only the two stations on the southeastern side of the barrier-but situated in the northeast of the region-(Esperanza and Marambio, the "east coast" stations: see Fig. 1) reveal strong relationships during summer. Esperanza actually has a higher correlation to the SAM in this season (0.47) than in autumn (0.40). Recent trends in the SAM have been largest in these two seasons and are also both statistically significant (cf. Table 1). Thus, these statistical relationships are indicative of the major role that the changing SAM is playing in driving climate change within the region.

Regression coefficients are larger in autumn than summer at all six peninsula stations (e.g., at Esperanza, $0.52^{\circ}$ and $0.21^{\circ} \mathrm{C}$, respectively, from the detrended data or $0.67^{\circ}$ and $0.28^{\circ} \mathrm{C}$, respectively from the original data). Those associated with the two stations east of the barrier are higher than the others in both seasons. However, the impact of the topographic barrier on controlling relative temperatures on either side of it is most pronounced in summer. In this season, the standard deviation of mean temperatures at the east coast stations is markedly greater than those immediately to the northwest, meaning that the ratio between their associated regression coefficients is larger than between the equivalent correlation coefficients. Values of the regression coefficients at Esperanza (east) and O'Higgins (northwest) are $0.21^{\circ}$ and $0.07^{\circ} \mathrm{C}$, respectively $\left(0.28^{\circ}\right.$ and $0.10^{\circ} \mathrm{C}$, respectively from the original data), indicating a threefold increase in the sensitivity of temperatures to changes in the SAM on crossing the barrier from west to east. This result is particularly striking as Esperanza and O'Higgins are situated only $50 \mathrm{~km}$ apart 
and the elevation of the orography between them does not exceed $500 \mathrm{~m}$. Moreover, at Orcadas, to the northeast of the peninsula (see Fig. 1), the relative magnitude of the seasonal relationships between the SAM and near-surface temperatures more closely resembles the two stations to the northwest rather than those to the east. Again, this suggests that the presence of the barrier plays a very important role in determining the magnitude that changes in the SAM have on summer temperatures across the peninsula region.

Note that in winter there are strong correlations between the SAM and temperatures at five stations but, interestingly, not at Faraday (cf. Table 3), the most southerly of the stations examined here where the warming in this season exceeds $5.8^{\circ} \mathrm{C}$ since 1950 . This indicates succinctly that the trend in the SAM has not played a significant role in driving the exceptional winter warming observed there. Indeed, given the negligible change in the winter SAM (cf. Table 1), then this finding is true for all stations in the region (cf. section $3 b)$.

Similar statistical coefficients (based on monthly data) were computed for the entire Antarctic continent by Kwok and Comiso (2002), using undetrended data, and by Schneider et al. (2004). Both studies used identical surface temperature datasets derived from infrared satellite data from 1982 to 1998 (1999 in the later study). Kwok and Comiso (2002) employed a SAM index based on the first EOF of $850-\mathrm{hPa}$ geopotential height from the NCEP-NCAR reanalysis (Thompson and Wallace 2000), while Schneider et al. (2004) used a similar SAM index based on $500-\mathrm{hPa}$ geopotential height.

The correlation coefficients obtained by Kwok and Comiso (2002) and those from the longer annual dataset of this study are of broadly similar magnitude, with maximum values of $\sim 0.5-0.6$ in the north and northeast peninsula and lower values on the west coast at the latitude of Faraday. However, we note that the regression coefficients in the peninsula region indicated in Fig. 3a of Kwok and Comiso (2002), with maximum values close to $2^{\circ} \mathrm{C}$ per unit change in the SAM, are significantly larger than both those derived in this study (cf. Table 3) and those depicted in Fig. 7a of Schneider et al. (2004), where maximum values in the northern peninsula are less than $1^{\circ} \mathrm{C}$. Repeating the analysis of monthly data using the Marshall (2003) SAM index produces values similar to the Schneider et al. (2004) results. Equivalent regression coefficients derived from monthly station observations are also of similar magnitude to those of Schneider et al. (2004).

Furthermore, we note that van den Broeke (2000) demonstrated a significant correlation between cloud cover and surface pressure at some Antarctic stations. Therefore, it is likely that the magnitude of the SAM will have some influence on cloud cover and this will be examined further in the forthcoming modeling paper (N. P. M. van Lipzig et al. 2006, unpublished manuscript). The satellite-derived surface temperatures in the peninsula region are a highly conditionally sampled record (King and Comiso 2003), because the region is very cloudy-77\% of Faraday observations report a cloud cover of 7 octas or greater for 1982-98-and temperatures can only be determined from cloud-free imagery. Thus, we suggest that the temperature dataset utilized by Kwok and Comiso (2002) is poorly suited for studying the relationship between the SAM and peninsula temperatures unless data gaps can be suitably filled (see Schneider et al. 2004).

\section{b. The contribution of changes in the SAM to regional near-surface warming}

The current positive trend in the summer SAM commenced in the mid-1960s (Marshall 2003): Fig. 1 shows the regional near-surface temperature trends contemporaneous with this change (1965-2000). In autumn, summer and, as a consequence annually, the two east coast stations, Esperanza and Marambio, underwent the largest warming in the peninsula region during this period. The other four Antarctic stations examined had their largest seasonal warming in winter, indicative of the far greater role that sea ice variability plays in determining temperatures on the north and, especially, the west coasts of the peninsula (e.g., King 1994; King et al. 2003; Jacobs and Comiso 1997).

Based on the observed changes in the SAM (Table 1), trends in near-surface temperatures (Fig. 1), and the computed regression coefficients (Table 3), Table 4 lists the estimated annual and seasonal temperature contributions of the SAM for 1965-2000. As the regression coefficients are derived from detrended data, these statistical results represent an estimate of the minimum contribution of changes in the SAM to near-surface temperature trends.

Annually, the recent trend in the SAM has caused similar temperature rises east and (north) west of the barrier (e.g., $0.19^{\circ} \mathrm{C}$ decade $^{-1}$ at Esperanza and $0.21^{\circ} \mathrm{C}$ decade $^{-1}$ at $\mathrm{O}^{\prime}$ Higgins), but has in fact contributed a greater percentage of the total warming to the latter region. However, with the exception of Faraday, at all stations the annual contribution is greater than $40 \%$ and at Punta Arenas exceeds 100\%, implying that some other form of climate change is having an opposite, cooling effect here. Given that in general the largest regression coefficients are calculated in autumn, it is not surprising that the biggest contribution by the SAM 
TABLE 4. Estimated contribution of the SAM to annual and seasonal temperature changes per decade and the percentage of total near-surface temperature change (in parentheses) caused by the positive trend in the SAM [1965-2000; except Bellingshausen (19682000) and Marambio (1970-2000)]. Temperature increases are in ${ }^{\circ} \mathrm{C}$ decade ${ }^{-1}$. Negative percentage values indicate that SAM-related temperature changes are opposite to the overall observed change.

\begin{tabular}{|c|c|c|c|c|c|c|c|c|c|c|}
\hline \multirow{2}{*}{$\frac{\text { Stations }}{\text { Bellingshausen }}$} & \multicolumn{2}{|c|}{ Annual } & \multicolumn{2}{|c|}{ Autumn (MAM) } & \multicolumn{2}{|c|}{ Winter (JJA) } & \multicolumn{2}{|c|}{ Spring (SON) } & \multicolumn{2}{|c|}{ Summer (DJF) } \\
\hline & 0.26 & (74) & 0.36 & $(71)$ & 0.03 & $(5)$ & 0.02 & $(-19)$ & 0.03 & (10) \\
\hline Esperanza & 0.19 & (40) & 0.49 & (49) & -0.01 & $(-2)$ & 0.04 & $(-40)$ & 0.23 & (35) \\
\hline Faraday & 0.00 & $(0)$ & 0.08 & (25) & -0.01 & $(-1)$ & -0.07 & $(-28)$ & -0.04 & $(-22)$ \\
\hline Marambio & 0.30 & (42) & 0.68 & (49) & 0.07 & (8) & 0.13 & $(-361)$ & 0.16 & (22) \\
\hline O'Higgins & 0.21 & (93) & 0.38 & (80) & -0.01 & $(-2)$ & 0.03 & $(-60)$ & 0.08 & (38) \\
\hline Orcadas & 0.19 & (55) & 0.35 & (68) & -0.01 & $(-2)$ & 0.02 & $(-51)$ & 0.05 & (13) \\
\hline Punta Arenas & 0.12 & $(167)$ & 0.01 & (15) & 0.00 & $(0)$ & 0.02 & (22) & 0.06 & (20) \\
\hline
\end{tabular}

to regional temperature changes is seen in this season, both in terms of the actual temperature change and the proportion of the total change (up to $80 \%$ ); Punta Arenas is the single exception here. The relatively small winter and spring trends in the SAM means that any resultant contribution to temperature change is small, and in many cases, it is negative (cf. Table 4). Other processes are playing a more dominant role in determining the region's temperatures in these seasons.

In summer, the changing SAM has contributed to a warming throughout the region, especially to the east coast stations, where the associated rise of between $\sim 0.20^{\circ} \mathrm{C}$ decade $^{-1}$ and $\sim 0.35^{\circ} \mathrm{C} \mathrm{decade}^{-1}$ (the latter derived from the original data) is more than twice that determined elsewhere. The detrended data indicate that the contribution of $0.23^{\circ} \mathrm{C}$ decade $^{-1}$ at Esperanza is almost 3 times that at $\mathrm{O}^{\prime}$ Higgins $\left(0.08^{\circ} \mathrm{C}\right.$ decade $\left.^{-1}\right)$, despite the proportion of warming due to SAM variability being greater at O'Higgins in this season. A similar ratio occurs with computations made using the original, undetrended data. This result is due to the larger SAM-temperature regression coefficients on the east coast, related to the larger standard deviation in seasonal temperatures. The close relationship between the summer SAM and Esperanza temperatures is shown in Fig. 4a, which compares the seasonal station nearsurface temperature record and the temperature explained by variability in the SAM. As well as the recent trend in the SAM being visible in the Esperanza temperatures, the latter also display a period of high values in the early 1960s and a subsequent rapid decline in the mid-1960s that are both distinct features in the time series of the summer SAM (Marshall et al. 2004; Jones and Widmann 2004). This plot further confirms that climate variability associated with the SAM has played a major role in determining northeast peninsula nearsurface summer temperatures for at least the last $50 \mathrm{yr}$. Figure $4 \mathrm{~b}$ also displays the close relationship between SAM and Esperanza temperatures during summer. The ERA-40 MSLP difference between warm and cold Es- peranza summers (see figure caption for details) produces a remarkable facsimile of the annular structure of the SAM. At Faraday, farther south and on the west coast, the estimated contribution of SAM variability to the summer warming is actually negative.

These results are similar to those of Thompson and Solomon (2002), who produced a map showing the contribution of the SAM to December-May (summerautumn) Antarctic near-surface temperatures from 1969 to 2000 (their Fig. 3, bottom-right panel). They used another SAM index-based on Antarctic 500-hPa geopotential height-and their temperatures were taken from the Climatic Research Unit $5^{\circ} \times 5^{\circ}$ gridded dataset (Jones and Moberg 2003), in which the temperature of a grid cell is determined by the mean anomaly of the stations lying within it. Of the stations examined in this study, it is possible to uniquely distinguish Faraday, Orcadas, and Punta Arenas in Fig. 3 of Thompson and Solomon (2002) but the four other stations are situated within the same grid cell. The mean of the autumn and summer contributions at Orcadas and Punta Arenas lie within the same $0.5^{\circ} \mathrm{C}$ bins in which they are shown in the Thompson and Solomon study while Faraday does not. The latter probably occurs because of the negative correlation between the summer SAM and Faraday near-surface temperatures $(-0.12)$, which is much larger in the detrended data than the original data as used by Thompson and Solomon. Results from this study demonstrate that while the coarse $5^{\circ} \times 5^{\circ}$ gridded dataset utilized by Thompson and Solomon (2002) is appropriate for examining SAMtemperature relationships over much of Antarctica, significant detail is masked within the peninsula region.

\section{c. The relationship between the $S A M$ and Bellingshausen free-air temperatures}

The change in free-air temperatures at Bellingshausen over the period 1969-98 as derived from radiosonde data are shown in Fig. 5a. These observations, which at pressure levels above the height of the 

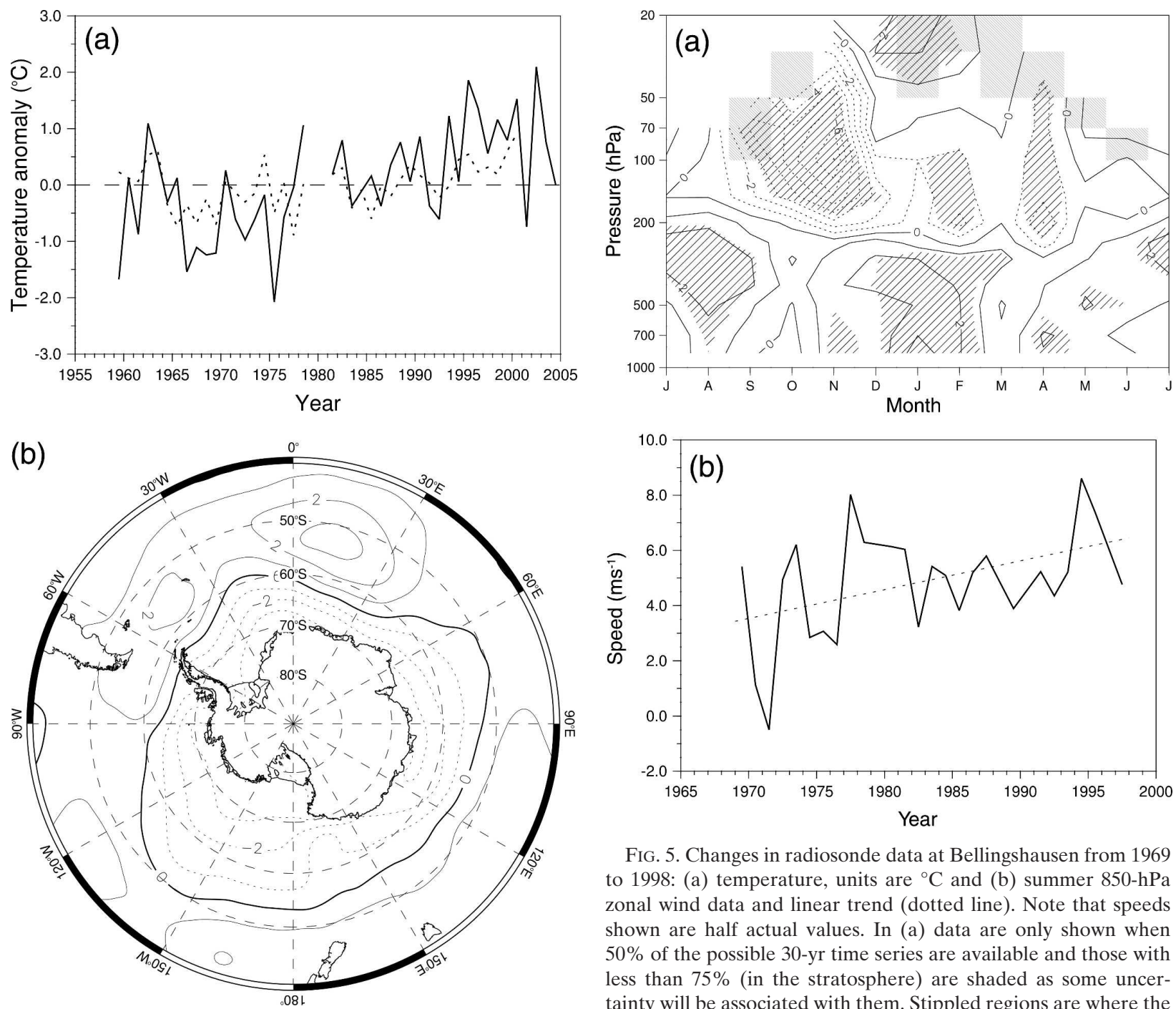

FIG. 5. Changes in radiosonde data at Bellingshausen from 1969 to 1998: (a) temperature, units are ${ }^{\circ} \mathrm{C}$ and (b) summer $850-\mathrm{hPa}$ zonal wind data and linear trend (dotted line). Note that speeds shown are half actual values. In (a) data are only shown when $50 \%$ of the possible $30-\mathrm{yr}$ time series are available and those with less than $75 \%$ (in the stratosphere) are shaded as some uncertainty will be associated with them. Stippled regions are where the changes are greater than one standard deviation of the respective monthly time series.

4. (a) The change in summer temperatures at Esperc (solid line) and the variations explained due to the trend in the SAM (dotted line) based on detrended data from 1965 to 2000. The correlation is 0.47 (significant at the $<1 \%$ level) and the regression coefficient is 0.20 ; i.e., the summer temperature at Esperanza will increase (decrease) by $0.20^{\circ} \mathrm{C}$ for every positive (negative) unit change in the SAM. (b) ERA-40 MSLP difference between the warmest and coolest third of summers at Esperanza based on detrended data from 1979 to 2000. Units are hPa.

peninsula $(<700 \mathrm{hPa})$ are reasonably representative of the northern peninsula (based on ERA-40 reanalysis data), demonstrate that there has been a general warming throughout the troposphere there. Above the tropopause $(\sim 250 \mathrm{hPa})$ there has been a cooling in the lower stratosphere and then at even greater altitude a region of warming in the summer at pressures less than $\sim 70 \mathrm{hPa}$ (unfortunately there are not enough data in winter to produce a reliable trend at these pressures). This figure can be compared to Fig. 1 of Thompson and

Solomon (2002), which is a composite for seven Antarctic stations located farther south than Bellingshausen and in East Antarctica, but encompasses the same time period as in Fig. 5a. The broad pattern of the temperature changes is similar between the two plots; for example, the stratospheric cooling associated with ozone loss in the austral spring is the dominant feature.

However, one important difference is that the tropospheric warming is much greater at Bellingshausen than the stations examined by Thompson and Solomon (2002), especially in summer. The 30-yr change from 1969 to 1998 is more than $2.4^{\circ} \mathrm{C}$ at $850 \mathrm{hPa}$, whereas the corresponding value for those stations much farther south is approximately $0^{\circ}$ (cf. Fig. 1 of Thompson and Solomon 2002). An equivalent value at Faraday is $1.4^{\circ} \mathrm{C}$, based on a temperature reconstruction (Marshall 
et al. 2002). These results show a similar spatial pattern to the near-surface summer temperatures in that the positive impact of the SAM is reduced as one moves poleward (cf. the Bellingshausen and Faraday data in Table 4). Thus, it seems likely that the SAM is also playing a significant role in determining free-air summer temperatures at Bellingshausen.

The maximum correlation between northern peninsula free-air temperatures and the SAM occurs at the height of the jet streams $(250-300 \mathrm{hPa})$. This height corresponds to the greatest contemporaneous increase in the tropospheric zonal winds above Bellingshausen in most months and reflects the southward movement of the main storm tracks during a positive SAM (e.g., Sinclair et al. 1997). However, within the general increase in tropospheric westerlies the summer trends in the lower troposphere $(>500 \mathrm{hPa})$ are the most statistically significant. As an example, the trend in the summer zonal wind component above Bellingshausen at $850 \mathrm{hPa}$ is shown in Fig. $5 \mathrm{~b}$.

\section{Climatology of summers with high and low SAM values}

It is clear from the results described in section 3 that the impact that the recent positive trend in the summer SAM has had on near-surface temperatures varies considerably, even over such a relatively small area as the northern Antarctic Peninsula region. In this section, composite ERA-40 reanalysis fields are used to help explain why these regional differences exist by comparing summers with high and low SAM values. Composite analysis of the detrended data is employed because it allows for the nonlinear aspects of climate linkagesunlike linear regression-and is a convenient way of showing differences in the wind field between high and low SAM summers. Note that because of the small number of samples in the two categories, appropriate statistics (e.g., Student's $t$ test) have not been calculated to determine how well separated they are. Instead, the main features described are common to all the summers in one category unless mentioned otherwise.

Examination of the bias in the MSLP and nearsurface temperature fields (Figs. 2 and 3 ) indicates that it is not until 1979 that all significant trends in the bias end (e.g., near-surface temperatures at Faraday; Fig. 3a). Therefore, the SAM was recalculated for summer data from 1979 to 2000 using the methodology described by Marshall (2003). Those summers with a detrended SAM index greater than 2 were considered to be "high SAM" years (1981, 1982, and 2000) and those with an index less than -2 were considered to be "low SAM" years (1985 and 1992) with the year referring to the January-February of the summer. The ERA-40 10-m wind fields for composites of high and low SAM summers are shown in Figs. 6a,b, respectively, and the difference is represented in Fig. 6c. Difference plots of MSLP, near-surface temperature and sea ice extent (data from NSIDC) are presented in Figs. 7a,b,c, respectively.

It is apparent from Figs. $6 \mathrm{c}$ and $7 \mathrm{a}$ that while the expected increase in zonal flow dominates the pattern of winds associated with an increase in the SAM, some significant regional meridional changes exist too. West of the peninsula, over the Amundsen-Bellingshausen Sea (ABS), the stronger westerlies associated with the high SAM summers force a southwestward movement of the climatological low relative to its position in low SAM summers, from $\sim 65^{\circ} \mathrm{S}, 83^{\circ} \mathrm{W}$ to $\sim 69^{\circ} \mathrm{S}, 86^{\circ} \mathrm{W}$ (cf. Figs. 6a,b). This, of course, relates to the southward migration of the principal regional storm track, the circumpolar trough, during high SAM summers, as discussed earlier. A similar pattern is also observed in NCEP-NCAR reanalysis MSLP data (Lefebvre et al. 2004; Liu et al. 2004). The 10-m wind vectors in the difference field that impinge on the northwest coast of the Antarctic Peninsula are essentially uniform westerly and have a velocity of $2-3 \mathrm{~m} \mathrm{~s}^{-1}$ (cf. Fig. 6c). Hence, the positive influence of the SAM on summer temperatures (cf. Table 3). However, during high SAM summers (cf. Fig. 6a) Faraday, unlike stations farther north (Bellingshausen and O'Higgins), lies south of the main band of westerlies and receives less advection of relatively warm air from the open ocean. This observation matches the findings in section 3: Faraday is too far south for summer temperatures there to be influenced positively by a stronger SAM.

Figure 6 confirms that in high SAM summers lowlevel air from the west is flowing over the northern peninsula, whereas in low SAM summers it is not. Hence, it validates the hypothesis proposed by Orr et al. (2004), that stronger westerlies associated with a more positive SAM will lead to the more frequent passage of air from west to east. Air masses passing over the northern peninsula will cause warming in the northeast simply because, climatologically, the peninsula barrier separates relatively warm maritime air to the west from relatively cool continental air to the east (e.g., see the mean annual temperature distribution in Plate $1 \mathrm{~b}$ of Morris and Vaughan 2003). Stably stratified air masses originating west of the barrier may be warmed additionally by the föhn effect (e.g., Klemp and Lilly 1975), which allows air originating from an elevated level upstream to reach the surface on the downstream side of the barrier and warm by adiabatic compression. One such episode in the northeast Antarctic Peninsula is 

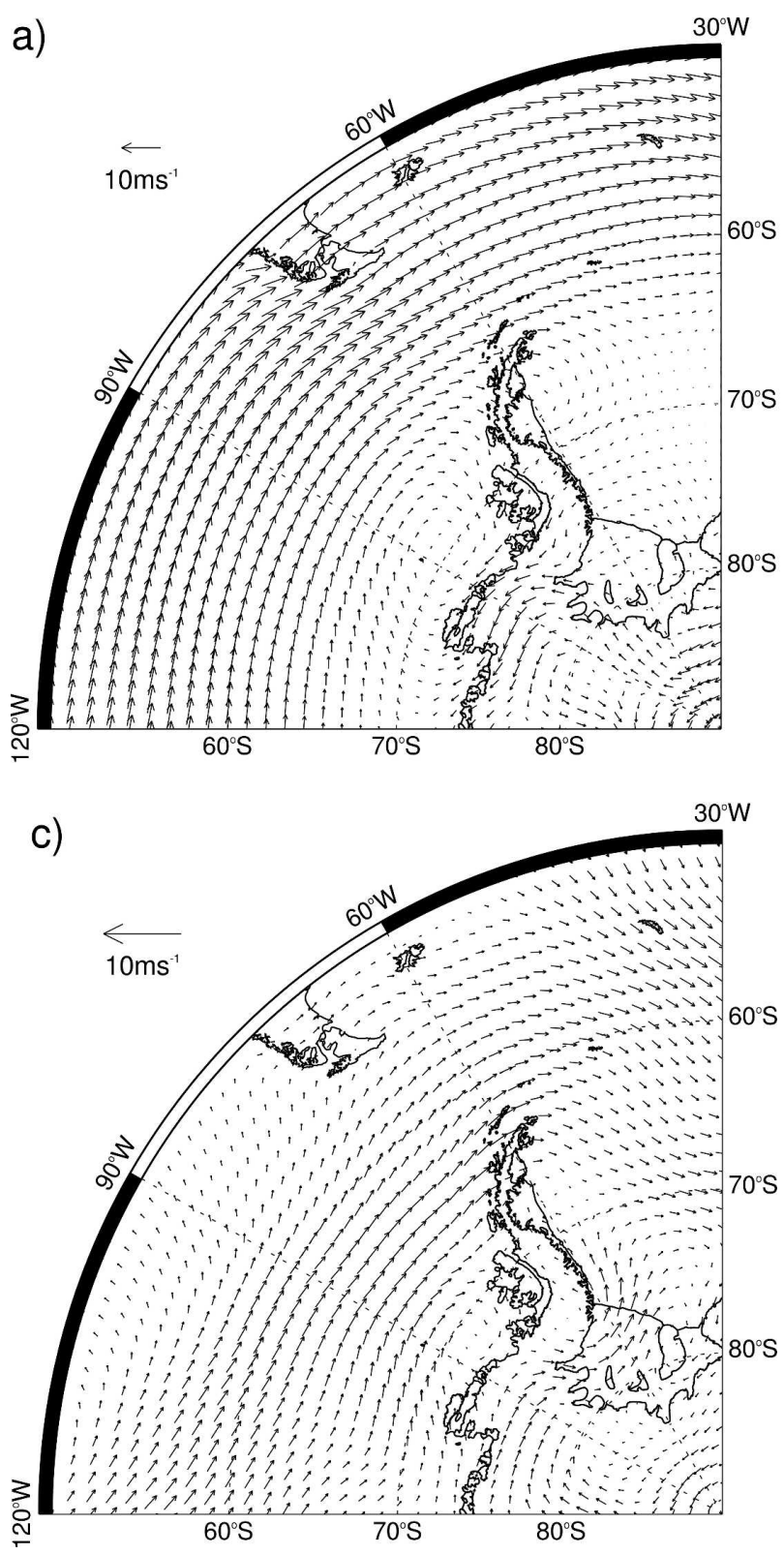

reported in detail in Schwerdtfeger (1984). The impact that air passing over the peninsula has on near-surface temperatures east of the barrier is confirmed by Fig. 7b, which illustrates the difference in near-surface temperatures between high and low SAM summers, and reveals a positive "bull's-eye" in the northeast peninsula that exceeds $0.5^{\circ} \mathrm{C}$. This feature, which is common to all high SAM summers, is further examined in section 5 using observations from Esperanza.

An interesting feature in Fig. $6 \mathrm{a}$ is the small cyclonic region located east of the Larsen Ice Shelf $\left(68^{\circ} \mathrm{S}\right.$, $\left.58^{\circ} \mathrm{W}\right)$, which is only apparent in high SAM summers (but can also be seen in Fig. 7a, the MSLP difference

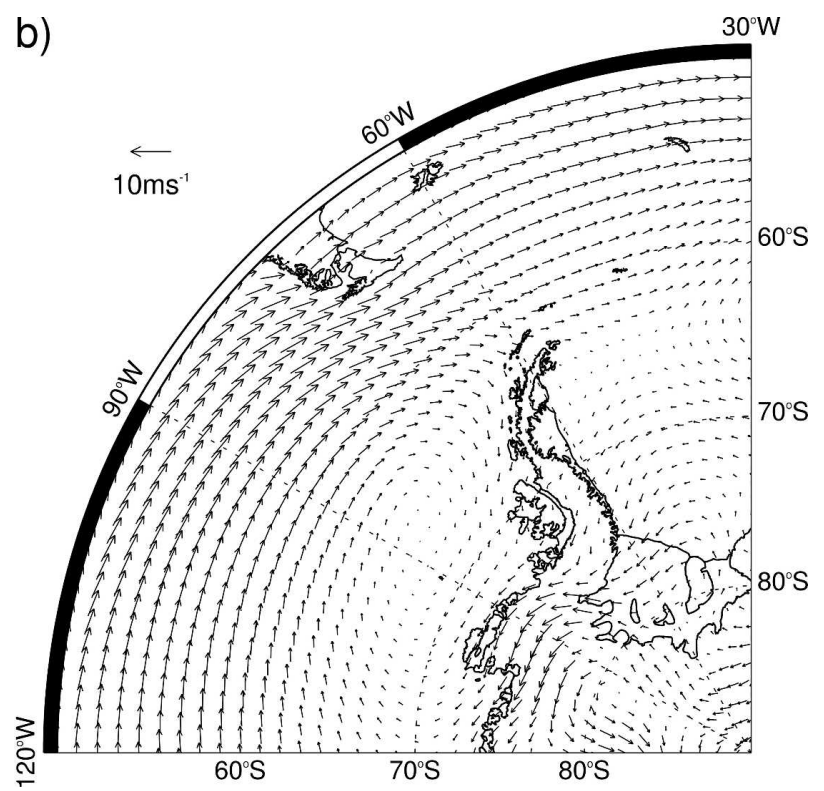

FIG. 6. ERA-40 10-m winds associated with (a) strongly positive SAM in summer (1981, 1982, and 2000); (b) strongly negative SAM in summer (1985 and 1992), and (c) the resultant difference plot. Strongly positive (negative) years (referring to the JanuaryFebruary) are defined as being greater than (less than) $+2(-2)$ based on a definition of the SAM from 1979 to 2000 that has been detrended. Units are $\mathrm{m} \mathrm{s}^{-1}$.

plot). Note that it is weak in 1982 and particularly pronounced in 2000. As it is located east of a major topographic barrier and associated with the passage of air over this barrier it seems highly likely that it represents lee cyclogenesis, a process known to occur in this area because of its associated cloud signature in satellite imagery (Turner et al. 1998). The conservation of potential vorticity means that once an air mass has passed over a barrier its trajectory will have cyclonic curvature and thus be deflected poleward (Holton 1992). This is suggested in the difference plot (Fig. 6c), which shows that the $10-\mathrm{m}$ winds immediately east of the peninsula and north of the location of the area of lee cyclogenesis 

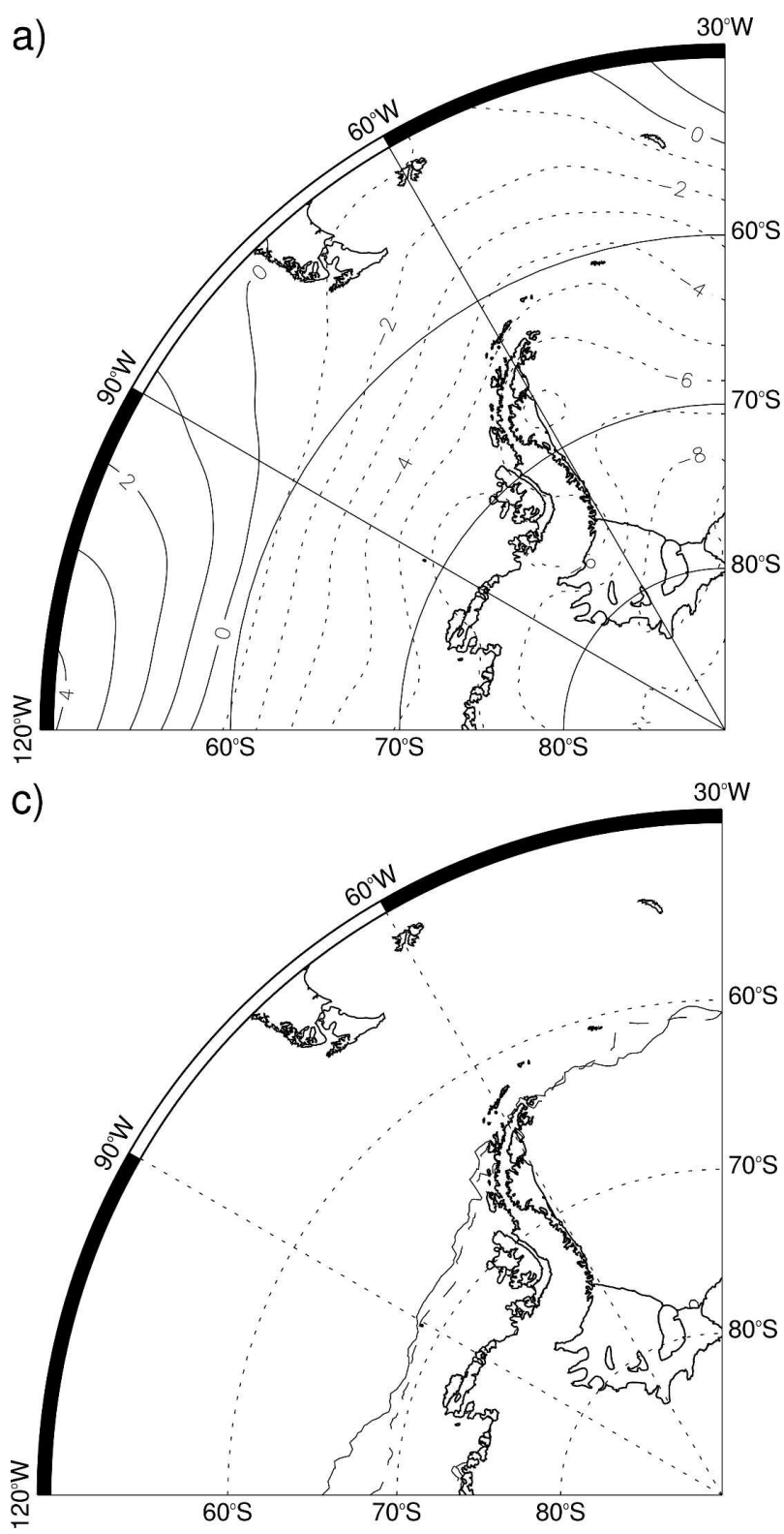

have veered relative to those west of the peninsula at the same latitude.

One note of caution regarding these results is that the steep, complex peninsula orography is significantly smoothed in ERA-40, in order that the spectral model remains numerically stable. In addition, the horizontal grid spacing $(\sim 125 \mathrm{~km})$ is not sufficient to represent the steep narrow barrier in much detail. This results in a lower and wider peninsula and, as a consequence, weather systems might pass over the peninsula in the reanalysis that did not do so in reality. Thus, integrations at high spatial resolution $(10-15 \mathrm{~km})$ are required to adequately resolve the barrier and study its full effect

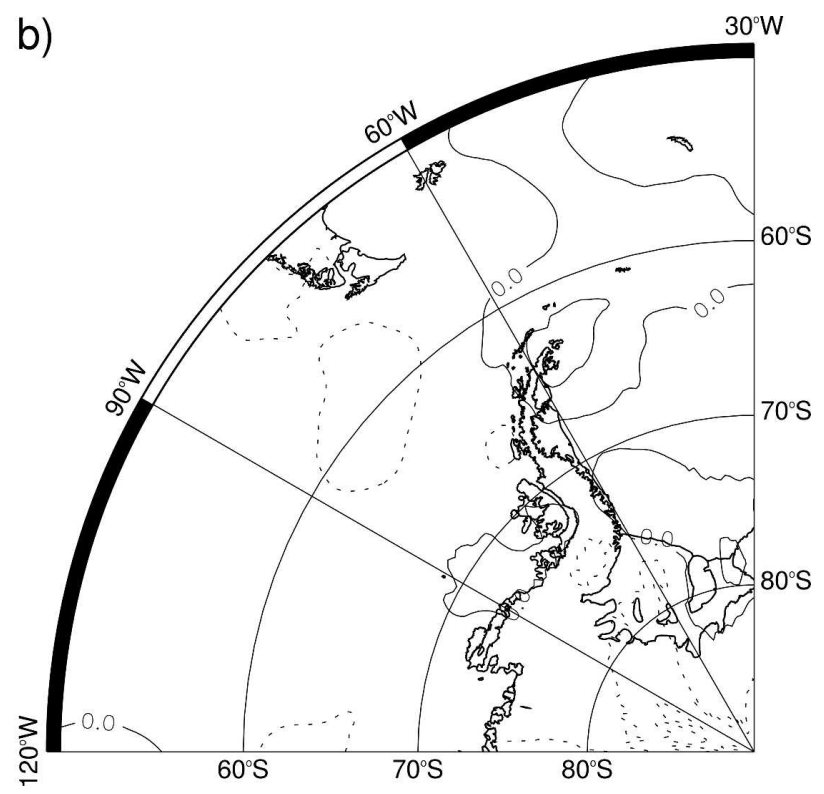

FIG. 7. Difference plots between strongly positive and negative summer SAM (see Fig. 6 caption) derived from ERA-40 data: (a) MSLP (units hPa), (b) near-surface temperature (units ${ }^{\circ} \mathrm{C}$ ), and (c) average sea ice extent in summers having a strongly positive (solid line) and negative (dashed line) SAM.

on the regional meteorology. For example, vertical velocities near the barrier are found to be much larger in a model integration using a grid spacing of $14 \mathrm{~km}$ compared to $1 \mathrm{~km}$ with a grid spacing of $55 \mathrm{~km}$ (van Lipzig et al. 2004). Such a high resolution would also help to identify the spatial extent of the föhn effect. Model integrations with appropriately high horizontal grid spacing are available (e.g., Orr et al. 2004; van Lipzig et al. 2004) and will be used to study the uncertainty related to the smoothed orography in ERA-40 in further papers (A. Orr et al. 2006, unpublished manuscript; N. P. M. van Lipzig et al. 2006, unpublished manuscript).

There appears to be greater offshore flow from the 
Ronne Ice Shelf $\left(76^{\circ} \mathrm{S}, 55^{\circ} \mathrm{W}\right)$ in the difference plot (Fig. 6c). Hence, in high SAM summers there is greater advection of cold continental air northward over the southeastern peninsula in direct contrast to what is happening in the northeast, as described previously. With the exceptions of this latter region and coastal Ellsworth Land, situated in the far southwest, much of the Antarctic Peninsula shows a slight summer cooling associated with high SAM, as revealed by the negative correlation at Faraday in Table 3.

Liu et al. (2004) showed that the circulation patterns associated with a positive SAM produce a strong poleward mean heat flux into the Bellingshausen Sea that limits sea ice growth. Similarly, Lefebvre et al. (2004) demonstrated a negative correlation between the SAM and Bellingshausen Sea sea-ice concentration taken from the First Hadley Centre Sea Ice and Sea Surface Temperature (HadISST1) dataset in the JanuaryMarch period for 1980-99. There is no evidence of this relationship from the limited years used to produce Fig. $7 \mathrm{c}$, with very similar mean summer sea ice extent immediately west of the peninsula in high and low SAM summers. Moreover, differences in extent immediately east of the peninsula, in the western Weddell Sea, are similarly small. The duration of the summer minimum in sea ice was also examined but, within the limitations of the monthly resolution of the NSIDC data, again there does not appear to be any significant differences related to the magnitude of the detrended SAM. The relatively small differences suggest that, in terms of governing the summer temperatures in the very northern part of the peninsula, SAM-related changes in the regional surface energy balance due to variations in sea ice extent and duration are less important than the increase in warm air advection due to stronger westerlies.

\section{Discussion and conclusions}

The two northernmost sections of the Larsen Ice Shelf collapsed in January 1995 and February-March 2002 , respectively, and these $2 \mathrm{yr}$ had the warmest summer temperatures on record at nearby Esperanza station (cf. Fig. 4a). This association provides a persuasive argument that rising summer temperatures in the northeast Antarctic Peninsula have played the major role in the breakup of the Larsen, by providing the surface meltwater necessary for crevasse propagation (Scambos et al. 2000, 2003; van den Broeke 2005). Furthermore, recent papers have suggested that, as a consequence of the ice shelf collapse, regional glaciers have accelerated, at least temporarily, leading to a minor rise in sea level (De Angelis and Skvarca 2003; Rignot et al. 2004).
In this study we have demonstrated that the recent positive change in the summer SAM and the resultant increase in the circumpolar westerlies are physical mechanisms responsible for increases in northern peninsula temperatures in this season. Near-surface summer temperatures at Esperanza are highly correlated with the SAM $(r=0.47-0.57$, significant at $<1 \%$ level $)$ with $35 \%-60 \%$ of the summer warming at Esperanza between 1965 and $2000\left(0.8^{\circ}-1.3^{\circ} \mathrm{C}\right)$ estimated as being due to changes in the SAM.

A comparison of similar statistics at other stations in the northern peninsula region demonstrates that the SAM has a far greater impact on near-surface temperatures on the eastern side than those on the west. In summer the regression coefficient between the SAM and Esperanza (east) temperatures is 3 times the equivalent value for O'Higgins (west), despite these two stations being separated by only $50 \mathrm{~km}$ and by orography less than $500 \mathrm{~m}$ MSL. The reasons for this marked variation in the sensitivity of regional temperatures to the SAM are linked to the higher standard deviation of temperatures east of the barrier, which, in turn, can be related to the hypothesis proposed by Orr et al. (2004). They suggested that (i) beyond a critical threshold velocity, low-level westerlies will pass over the peninsula rather than be blocked; and hence (ii) with the stronger summer westerlies associated with a positive trend in the SAM, this scenario has occurred more frequently. Some indication of this can be seen in the ERA-40 surface wind fields (Fig. 6), which show evidence of winds passing over the barrier-cyclonic curvature of winds east of the peninsula and lee cyclogenesis-only in "high SAM" summers. There are two principal reasons why the westerly advection of an air mass across the peninsula will lead to greater temperature increases on the eastern side. First, climatologically, temperatures at a given latitude tend to be approximately $1^{\circ}-2^{\circ} \mathrm{C}$ warmer on the western side (warmer maritime air) than on the east (cooler continental air) so the warming in the east will be similarly greater. Second, a föhn effect may cause further warming of air masses crossing the barrier and descending, and this has been linked to enhanced surface melting on the Larsen Ice Shelf (van den Broeke 2005).

To quantify the effect that the passage of air over the peninsula has on near-surface temperatures east of the barrier we compare near-surface observations of winds and temperature during the summer at Esperanza. The data comprise 6-hourly SYNOP observations and encompass 16 summers from 1989 to 2004. Figure 8 shows wind roses associated with temperatures above and below $1.1^{\circ} \mathrm{C}$, the long-term (1945-present) upper-quartile summer temperature at Esperanza. Strong downslope 
a)

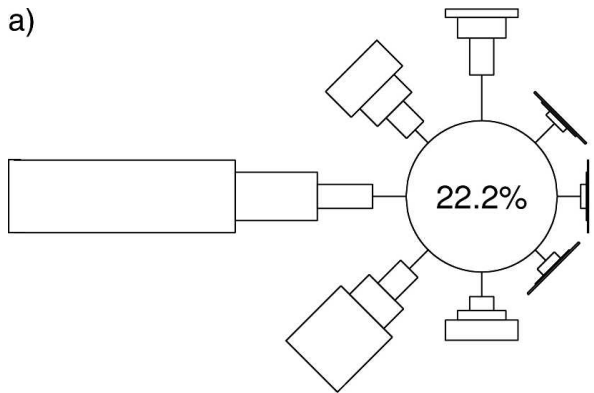

Wind speed divided into $2.5 \mathrm{~ms}^{-1}$ bins

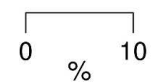

b)

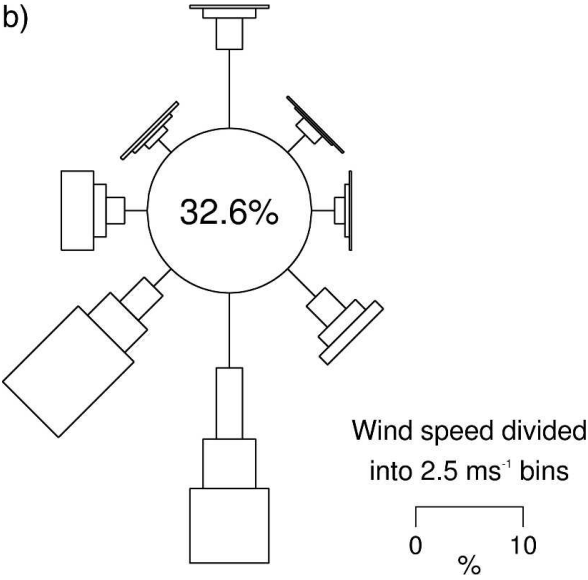

FIG. 8. Wind roses when near-surface summer temperatures at Esperanza are (a) $>1.1^{\circ} \mathrm{C}$ and $(\mathrm{b}) \leq 1.1^{\circ} \mathrm{C}$. The period of analysis is December 1988-February 2004.

westerly winds, which result from air passing over the peninsula, are dominant when the temperature is high (mean vector speed and direction are $4.6 \mathrm{~m} \mathrm{~s}^{-1}$ and $267^{\circ}$, respectively) whereas during colder conditions the mean flow is weaker and more southerly (mean vector speed and direction are $2.8 \mathrm{~m} \mathrm{~s}^{-1}$ and $210^{\circ}$, respectively). Another way of considering these data is that the mean summer temperature associated with strong westerly winds (defined as having a speed greater than $10 \mathrm{~m} \mathrm{~s}^{-1}$ and a direction between $247.5^{\circ}$ and $292.5^{\circ}$ ) is $3.2^{\circ} \mathrm{C}$ whereas for all the data it is $1.1^{\circ} \mathrm{C}$. Clearly, higher temperatures at Esperanza are commonly associated with the passage of air over the orographic barrier, as suggested by the ERA-40 data during high SAM summers (Figs. 6c and 7b). The correlation coefficient between the frequency of westerly winds at Esperanza during summer and the mean monthly CPC SAM index for 1989-2004 is 0.70, significant at the $<1 \%$ level. Hence, this limited observational dataset supports the hypothesis that changes in the SAM have contributed significantly to the recent marked summer warming observed east of the barrier through increased advection of air masses over the northern Antarctic Peninsula.

In addition, the SAM plays a role in controlling summer near-surface temperature variability at stations that are located west of the barrier in the very northern part of the Antarctic Peninsula. The Bellingshausen upper-air dataset reveals that this is also true throughout the troposphere.

While the observational statistics utilized in this study provide information on the physical relationships between the SAM and northern peninsula temperatures, they cannot be used to examine in detail the mechanisms behind these associations, such as the apparent role of the föhn effect. In this study, we have attempted to gain further insight by using various fields from the ERA-40 reanalysis. However, due to the relatively poor representation of the peninsula orography in the model used-too wide and shallow-some doubt remains regarding the exact nature and magnitude of the processes described. Therefore, in companion papers (A. Orr et al. 2006, unpublished manuscript; N. P. M. van Lipzig et al. 2006, unpublished manuscript) we will utilize mesoscale numerical weather prediction models and regional climate models with a grid spacing of about $10-15 \mathrm{~km}$, which more accurately represent the peninsula orography and so are better able to provide accurate diagnostics regarding the role of the changing SAM on Antarctic Peninsula summer temperatures.

Given that modeling studies indicate that the observed change in the summer SAM is predominantly a response to anthropogenic forcing (e.g., Kushner et al. 2001; Gillett and Thompson 2003; Marshall et al. 2004), then the physical mechanisms outlined in this paper enable this climatic change to be linked directly to the Larsen Ice Shelf disintegration and any consequent sea level rise. While other processes, such as oceanographic effects, may have also played a role in this ice shelf breakup, our study does suggest that human activity is impacting the global climate system through modification of Antarctic atmospheric circulation patterns.

Acknowledgments. We acknowledge the contribution of the three anonymous reviewers for their comments that helped to improve the manuscript, particularly the statistical analyses; we thank them for their effort on our behalf.

\section{REFERENCES}

Bromwich, D. H., and R. L. Fogt, 2004: Strong trends in the skill of the ERA-40 and NCEP-NCAR reanalyses in the high and 
middle latitudes of the Southern Hemisphere. J. Climate, 17, 4603-4619.

Carvalho, L. M. V., C. Jones, and T. Ambrizzi, 2005: Opposite phases of the Antarctic Oscillation and relationships with intraseasonal to interannual activity in the Tropics during the austral summer. J. Climate, 18, 702-718.

Comiso, J. C., 1995: SSM/I concentrations using the Bootstrap Algorithm. NASA Ref. Publ. 1380, 49 pp.

De Angelis, H., and P. Skvarca, 2003: Glacier surge after ice shelf collapse. Science, 299, 1560-1562.

Domack, E., and Coauthors, 2005: Stability of the Larsen B ice shelf on the Antarctic Peninsula during the Holocene epoch. Nature, 436, 681-685.

Gillett, N. P., and D. W. J. Thompson, 2003: Simulation of recent Southern Hemisphere climate change. Science, 302, 273-275.

Gong, D., and S. Wang, 1999: Definition of Antarctic oscillation index. Geophys. Res. Lett., 26, 459-462.

Hansen, J., R. Ruedy, M. Sato, M. Imhoff, W. Lawrence, D. Easterling, T. Peterson, and T. Karl, 2001: A closer look at United States and global surface temperature change. J. Geophys. Res., 106, 23 947-23 963.

Holton, J. R., 1992: An Introduction to Dynamic Meteorology. 3d ed. Academic Press, $511 \mathrm{pp}$.

Jacobs, S. S., and J. C. Comiso, 1997: Climate variability in the Amundsen and Bellingshausen Seas. J. Climate, 10, 697-709.

Jones, J. M., and M. Widmann, 2004: Early peak in Antarctic oscillation index. Nature, 432, 290-291.

Jones, P. D., and A. Moberg, 2003: Hemispheric and large-scale surface air temperature variations: An extensive revision and an update to 2001. J. Climate, 16, 206-223.

King, J. C., 1994: Recent climate variability in the vicinity of the Antarctic Peninsula. Int. J. Climatol., 14, 357-369. and J. C. Comiso, 2003: The spatial coherence of interannual temperature variations in the Antarctic Peninsula. Geophys. Res. Lett., 30, 1040, doi:10.1029/2002GL015580.

—, J. Turner, G. J. Marshall, W. M. Connolley, and T. A. Lachlan-Cope, 2003: Antarctic Peninsula climate variability and its causes as revealed by instrumental records. Antarctic Peninsula Climate Variability, E. Domack et al., Eds., Antarctic Research Series, Vol. 79, Amer. Geophys. Union, $17-30$.

Klemp, J. B., and D. R. Lilly, 1975: The dynamics of wave-induced downslope winds. J. Atmos. Sci., 32, 320-339.

Kushner, P. J., I. M. Held, and T. L. Delworth, 2001: Southern Hemisphere atmospheric circulation response to global warming. J. Climate, 14, 2238-2249.

Kwok, R., and J. C. Comiso, 2002: Spatial patterns of variability in Antarctic surface temperature: Connections to the Southern Hemisphere Annular Mode and the Southern Oscillation. Geophys. Res. Lett., 29, 1705, doi:10.1029/2002GL015415.

Lanzante, J. R., 1996: Resistant, robust and non-parametric techniques for the analysis of climate data: Theory and examples including applications to historical radiosonde station data. Int. J. Climatol., 16, 1197-1226.

Lefebvre, W., H. Goosse, R. Timmermann, and T. Fichefet, 2004: Influence of the Southern Annular Mode on the sea iceocean system. J. Geophys. Res., 109, C09005, doi:10.1029/ 2004JC002403.

L'Heureux, M. L., and D. W. J. Thompson, 2006: Observed relationships between the El Niño-Southern Oscillation and the extratropical zonal-mean circulation. J. Climate, 19, 276-287.

Liu, J., J. A. Curry, and D. G. Martinson, 2004: Interpretation of recent Antarctic sea ice variability. Geophys. Res. Lett., 31, L02205, doi:10.1029/2003GL018732.

Marshall, G. J., 2002: Analysis of recent circulation and thermal advection change in the northern Antarctic Peninsula. Int. J. Climatol., 22, 1557-1567.

, 2003: Trends in the Southern Annular Mode from observations and reanalyses. J. Climate, 16, 4134-4143.

_, V. Lagun, and T. A. Lachlan-Cope, 2002: Changes in Antarctic Peninsula tropospheric temperatures from 1956 to 1999: A synthesis of observations and reanalysis data. Int. J. Climatol., 22, 291-310.

- , P. A. Stott, J. Turner, W. M. Connolley, J. C. King, and T. A. Lachlan-Cope, 2004: Causes of exceptional circulation changes in the Southern Hemisphere. Geophys. Res. Lett., 31, L14205, doi:10.1029/2004GL0199952.

Met Office, 1979: Handbook of Weather Messages Part III Coding. 6th ed. Her Majesty's Stationary Office, $136 \mathrm{pp}$.

Morris, E. M., and D. G. Vaughan, 2003: Spatial and temporal variation of surface temperature on the Antarctic Peninsula and the limit of viability of ice shelves. Antarctic Peninsula Climate Variability, E. Domack et al., Eds., Antarctic Research Series, Vol. 79, Amer. Geophys. Union, 61-68.

Orr, A., D. Cresswell, G. J. Marshall, J. C. R. Hunt, J. Sommeria, C. G. Wang, and M. Light, 2004: A "low-level" explanation for the recent large warming trend over the western Antarctic Peninsula involving blocked winds and changes in zonal circulation. Geophys. Res. Lett., 31, L06204, doi:10.1029/ 2003 GL019160.

Rignot, E., G. Casassa, P. Gogineni, W. Krabill, A. Rivera, and R. Thomas, 2004: Accelerated ice discharge from the Antarctic Peninsula following the collapse of Larsen B ice shelf. Geophys. Res. Lett., 31, L18401, doi:10.1029/2004GL020697.

Santer, B. D., T. M. L. Wigley, J. S. Boyle, D. J. Gaffen, J. J. Hnilo, D. Nychka, D. E. Parker, and K. E. Taylor, 2000: Statistical significance of trends and trend differences in layeraverage atmospheric temperature time series. J. Geophys. Res., 105, 7337-7356.

Scambos, T. A., C. Hulbe, M. Fahnestock, and J. Bohlander, 2000: The link between climate warming and break-up of ice shelves in the Antarctic Peninsula. J. Glaciol., 46, 516-530.

,$- \ldots$, and — 2003: Climate-induced ice shelf disintegration in the Antarctic Peninsula. Antarctic Peninsula Climate Variability, E. Domack et al., Eds., Antarctic Research Series, Vol. 79, Amer. Geophys. Union, 79-92.

_ J. A. Bohlander, C. A. Shuman, and P. Skvarca, 2004: Glacier acceleration and thinning after ice shelf collapse in the Larsen B embayment, Antarctica. Geophys. Res. Lett., 31, L18402, doi:10.1029/2004GL020670.

Schneider, D. P., E. J. Steig, and J. C. Comiso, 2004: Recent climate variability in Antarctica from satellite-derived temperature data. J. Climate, 17, 1569-1583.

Schwerdtfeger, W., 1984: Weather and Climate of the Antarctic. Elsevier, $261 \mathrm{pp}$.

Shepherd, A., D. Wingham, T. Payne, and P. Skvarca, 2003: Larsen Ice Shelf has progressively thinned. Science, 302, 856859.

Shindell, D. T., and G. A. Schmidt, 2004: Southern Hemisphere climate response to ozone changes and greenhouse gas increases. Geophys. Res. Lett., 31, L18209, doi:10.1029/ 2004 GL020724.

Sinclair, M. R., J. A. Renwick, and J. W. Kidson, 1997: Lowfrequency variability of Southern Hemisphere sea level pres- 
sure and weather system activity. Mon. Wea. Rev., 125, 25312543.

Thompson, D. W. J., and J. M. Wallace, 2000: Annular modes in the extratropical circulation. Part I: Month-to-month variability. J. Climate, 13, 1000-1016.

, and S. Solomon, 2002: Interpretation of recent Southern Hemisphere climate change. Science, 296, 895-899.

Turner, J., G. J. Marshall, and T. A. Lachlan-Cope, 1998: Analysis of synoptic-scale low pressure systems within the Antarctic Peninsula sector of the circumpolar trough. Int. J. Climatol., 18, 253-280.

- and Coauthors, 2004: The SCAR READER project: Toward a high-quality data base of mean Antarctic meteorological observations. J. Climate, 17, 2890-2898.

— - and Coauthors, 2005: Antarctic climate change during the last 50 years. Int. J. Climatol., 25, 279-294.

Uppala, S. M., and Coauthors, 2005. The ERA-40 re-analysis. Quart. J. Roy. Meteor. Soc., 131, 2961-3012.

van den Broeke, M. R., 2000: The semi-annual oscillation and
Antarctic climate. Part 3: The role of near-surface wind speed and cloudiness. Int. J. Climatol., 20, 117-130.

_ 2005: Strong surface melting preceded collapse of Antarctic Peninsula ice shelf. Geophys. Res. Lett., 32, L12815, doi:10.1029/2005GL023247.

- and N. P. M. van Lipzig, 2003: Response of wintertime Antarctic temperatures to the Antarctic Oscillation: Results of a regional climate model. Antarctic Peninsula Climate Variability, E. Domack et al., Eds., Antarctic Research Series, Vol. 79, Amer. Geophys. Union, 43-58.

van Lipzig, N. P. M., J. C. King, T. A. Lachlan-Cope, and M. R. van den Broeke, 2004: Precipitation, sublimation and snowdrift in the Antarctic Peninsula region from a regional atmospheric model. J. Geophys. Res., 109, D24106, doi:10.1029/ 2004JD004701.

Vaughan, D. G., and Coauthors, 2003: Recent rapid regional climate warming on the Antarctic Peninsula. Climate Change, 60, 243-274. 